\title{
Reconsidering Intercultural Communication Competence Development in Different Social Patterns - Starting from the Study of Greetings
}

\author{
Linqi Liu \\ Beijing University of Posts and Telecommunications, Beijing, China
}

\begin{abstract}
Greeting is a universal phenomenon in human life and part of people's daily communication. Greeting can be described as the exchange of expressions, pleasantries or good wishes between two people interacting for the purpose of fulfilling social obligations, or for the establishment of interpersonal relationships. It occurs at the beginning of an interaction or as a sign of its closing. They are linguistic routines that form part of the repertoire of politeness. Greetings regulate the behavior patterns of each other in social interaction. They are an integral part of interactional discourse and serve as prelude to the establishment of social relationships. However, how to visualize and how to realize it will most probably be culture-specific. The use of greetings in intercultural communication is much more problematic than what people may think. It is necessary for us to understand and strengthen our intercultural communication competence.
\end{abstract}

\section{Introduction}

Language is a social phenomenon. Language connects people to each other in social relationships and allows them to participate in a variety of activities in everyday life [1]. Language system does not exist in the system of independent development. It restricts social elements so that people's language forms and language elements within the system are associated with each other, arranged in an intercross pattern.

The things, for any member of a society, needs to be mastered far more than the formal features and structures of the language. People must learn about the social and cultural value of knowledge, the social constraints in behavior, including constraints on the language behavior.

Greetings are linguistic routines that form part of the repertoire of politeness [2]. It has been referred to as an "interactional ritual" [3], "an interactional routine" [2], or a conventionalized episode of interaction in the opening phase of a conversation [4].

Differences in English and Chinese greetings are remarkable. "Good morning/ afternoon/ evening" are common greeting expressions in English, whereas "Have you eaten" "Where are you going?" are common greetings in Chinese.

The study aims to start from discussing the role of greetings in different social patterns and make a better understanding of English and Chinese greetings. It also considers possible implication of the study for intercultural communication and English teaching and learning. Influence of culture value in different social patterns is the focus of attention.

\section{Literature Review}

Several parameters involved in greeting exchanges as a speech event, according to academics across the three disciplines, linguistics, sociology, and anthropology, are mixed. Linguists represent the micro view, focusing on linguistic behavior. Sociologists take a step back by looking more at social interaction. Anthropologists have taken a larger view, interpreting the linguistic behavior of greetings linked with interaction as representing culture.

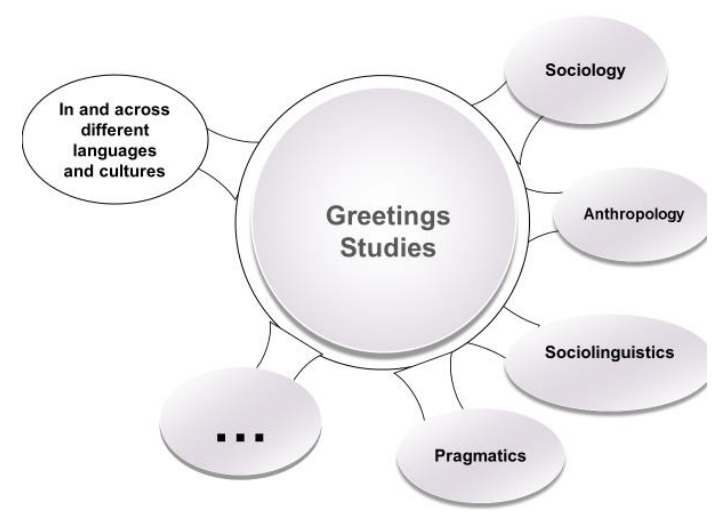

Figure 1. Study motivation

\subsection{From linguistic perspective}

Dell Hymes points out that the ability to produce grammatical sentences is only one aspect of the competence of the speaker. Even if a speaker has a very good syntactic ability, he or she still cannot communicate successfully with other members of the speech community unless he or she is in possession of knowledge concerning what is appropriate to say in specific situations [5].

Schegloff and Sacks see greetings as a speech event composed of two parts side by side, serial, and sequential, such as Greeting - Greeting. There may also be optional second pair parts where the second function is replaced by another function: Greeting-Request for Information [6]. Richards and Schmidt 
define Greeting - Greeting adjacency pairs as "closed sets, formulaic, and easily learned" [7]. They also acknowledge greeting-other function combinations as another possibility, and also point out that these other forms are not normally found in second language instruction.

\subsection{From sociolinguistic perspective}

Erving Goffman prefers to characterize greeting exchanges as "access rituals" consisting of two types, passing greetings and engaging greetings [8]. Goffman makes three generalizations in interpreting greeting behavior. First, exchanges serve to reestablish social relations; second, acknowledgement of a "differential allocation of status"; and third, when greetings are performed between strangers, "there is an element of guarantee for safe passage" [9].

Firth refers to greeting phenomena as ritual with verbal and non-verbal forms. Verbal forms may be one of three linguistic units: question ("How do you do?"), interjection ("Hello") or affirmation ("Good morning") and non-verbal forms are composed of body language. Firth claims greeting exchanges are an "affirmation" of social status [10]. Laver recognizes the social control element through status in society, but also adds that greetings may be negotiated between participants. Laver also proposes that routine rituals serve to preserve face.

Laver makes a further study of the rationale for the existence of routine elements such as greetings in the linguistic patterns of conversation [2]. Greetings as conversational routines are part of the linguistic repertoire of politeness. They are tools of polite behavior and their use is guided by a polite norm. He also summarizes social factors on the choice of greetings. In his framework, such social factors as age, kinship, acquaintance, generation, rank, setting and dispensation were taken into consideration. However, his analysis is tentative and calls for further empirical work.

Brown and Levinson put forward their model of politeness [11]. Their model of politeness is applied to the analysis of the corpus of greetings in English and Chinese. The central concept they employ in their model is that of "face" after Goffman. Influenced by Durkheim's distinction between negative and positive rituals, they distinguish two components of face, negative face and positive face. According to them, there are five strategies for the purpose of maintaining the interactants' negative face or enhancing their positive face. However, Brown and Levinson have not discussed greetings in their framework in detail.

Using Brown and Levinson's notions of face in politeness behavior, Laver argues that greeting exchanges constitute routine and thus politeness behavior. Because social interaction causes risk to face, the use of politeness, i.e., greeting exchanges, helps mediate the potential for loss of face.

\subsection{From anthropological linguistic perspective}

In the late 80 s, last century, Fieg and Mortlock offered their interpretation of greetings from crosscultural viewpoint. Greeting forms are defined as "ritualistic expressions" that carry some type of pragmatic meaning. What the meaning is, according to the authors, depends on the speech events as they present them. No explicit linguistic form is given other than examples from personal observation. [12] They attempt to generalize the utility of greetings initially as the result of influences of social factors, and then point out cross-cultural differences, such as how each culture's cosmological views influence the meaning of their speech act. The theoretical concerns revolve around notions of culture and provide underlying explanations of purpose. Greetings, in short, are a speech event with pragmatic meaning and the meaning, in turn, is affected by cultural perspectives [12].

\subsection{Studies of greetings in China}

Compared with the study abroad, research on greetings in China is carried out much later. Most works are focused on vocatives. The real study of politeness in linguistics began in the 1980s when pragmatics was introduced into China. The past two decades has witnessed the progress of Chinese politeness research, which consisted mainly of attempts at testing the validity of the claimed universality of Western politeness theories, exploring the features of Chinese politeness and formulating its own theories. Some scholars, such as Liu Runqing and He Zhaoxiong, have introduced the findings of politeness study in the West; several other scholars have made some modifications of the Western politeness theories. For example, Gu Yueguo has made a contrastive analysis of politeness phenomenon between Chinese and English and has pointed out the cultural difference in politeness phenomenon. Jia Yuxin made a comparison of interpersonal relationship and intercultural communication between the East and the West.

As for greetings, Qian Housheng carried out a contrastive study of linguistic routines and politeness on greetings and partings in English and Chinese. He also makes some modification on the existing models and framework. However, since the informants in his study are all Chinese studying abroad, the data he collected are not very comprehensive. 


\section{Interactivity and communication in different social patterns}

\subsection{Social power and social distance}

A great number of terms have been used in the literature for different dimension; only a few researchers have given explicit definitions of the term power. Spencer-Oatey [13] makes a comparison of the terms related to power. Judging from the different terms used for expressing the meaning of power, it seems that in their interpretation of the vertical dimension of interlocutor relations researchers have emphasized one or more of following aspects:

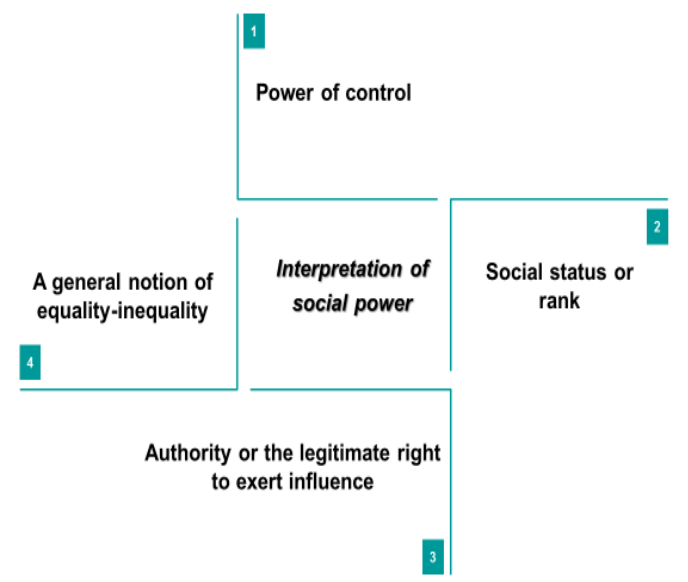

Figure 2. Figure 2. Interpretation of social power (Spencer-Oatey)

When there is power difference, the use of greeting between the participants is mainly governed by age and occupational status. In this research, the meaning of power covers the four components and is manifested in the factors of occupational status and age.

Age influences people's speech act strongly. People of different ages may have different characteristics of speech. Age is one of the significant factors in affecting the choice of greetings, and is a factor of power. People of different ages greet others differently. In a society where seniority is emphasized, older age implies power and higher social status.

Social distance is used most often as the main labels. However, a considerable number of other terms are also used: solidarity, closeness, familiarity and relational intimacy. This variation in terminology raises the question as to whether the terms are all equivalent, or whether different researchers conceptualize the "horizontal" dimension of interlocutor relations in slightly different ways.
After an examination of a number of pragmatic studies, judging from the various terms, definitions, Spencer-Oatey [13] has variously interpreted distance as comprising one or more of the following (often overlapping) components:

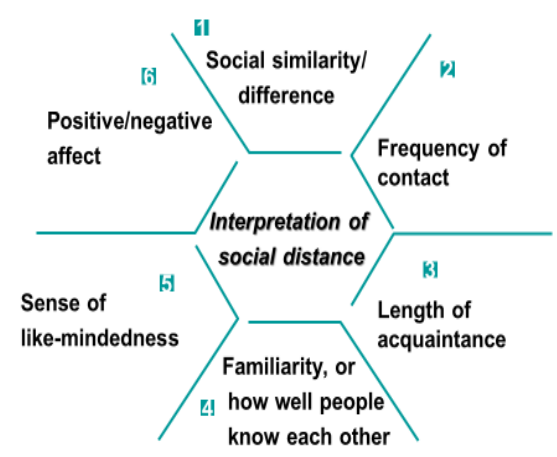

Figure 3. Interpretation of social distance (SpencerOatey)

When there is horizontal distance between the participants, such as relationship between two governmental officials of different nations, their relationship will be described as plus distance. When there is no horizontal disparity between participants, such as distance between two close friends, we consider their relationship to be minus distance.

Greetings not only vary strategically but also in degree of politeness. Some social factors as religious commitment, generation and rank should be taken into consideration. They are determiners of a set of specified greeting expressions ranging from politer to less polite. We should also take into consideration such factors as setting and dispensation.

\subsection{Cultural value realization}

People believe that culture evolves for the same reasons. It provides the basic need for us to establish a predictable world, in which each one of us is firmly rooted and thus we can understand the environment around us. From the moment a child is born, culture formally and informally teaches it how to behave in an acceptable way to an adult. Therefore, a member of culture does not need to expend energy to decide what every event means or how to respond to it. Generally, all people who have common culture can act behave correctly, automatically and predictably. As a result, culture provides a blueprint for all social activities to protect people from the unknown.

Sociological observation shows that most of the greetings are highly conventional, especially from cross-cultural studies, which are easy to be generalized by specific cultural customs. In a broad 
sense, greeting behavior can be called ritual, since it follows a regular practice; it is system of signs to convey external information; it is recognized by strong moral expression, and it has adaptive value in promoting social relations.

\subsubsection{Western culture and politeness. Westerners} value others as well as themselves and strive for equality in interpersonal relationships. It is easy to be reflected by assertiveness.

The term "individualism" refers to a cultural pattern consisting of loosely linked individuals, who conceive of themselves essentially as independent of collectives and who give precedence to their personal goals over others. According to Samovar and Porter [14], in its broad sense, "individualism" is the doctrine that an individual's interests ought to be paramount, and that all values, rights and duties originate in individuals.

Similarly, Fieg holds that this term involves selfconcept, the idea that the self is an individual unit whose behavior is aimed at individual goals as opposed to a member of a group whose behavior is aimed at smooth interpersonal relations [12].

In this sense, it is very difficult to give the word in a satisfactory translation in Chinese since the term is often related to the Chinese environment, hedonism and selfish. Opposite to Chinese cultural values and hence it is attributed to a derogatory sense by the Chinese, which is an English cultural dominant value orientation and rooted in the minds of the people.

The individualism factor and low power distance have both a direct and an indirect effect on communicational behaviors of members of English culture and thus influence the way English people show politeness when handling interpersonal relationships.

English speakers are known to be rather more considerable. They are particularly sensitive about their negative face as well. Questions such as "Where are you going?" or "What are you doing?" which sound impeding may not be proper to most of them, and thus are not accepted as greetings.

3.2.2. Eastern culture and Limao. The major outstanding characteristics of collectivism in Chinese culture are "we" consciousness and collectivityorientation [15]. The Chinese people attach great importance to the identity of "we", the interests, obligations and commitments of the group. They give priority to group goals, not personal goals. The core construction of collectivism is the collective unconsciousness of "connected self". That is, Chinese people perceive themselves as interdependent self, emphasizing "status, roles and relationships, belonging and fitting in, occupying one's proper place and engaging in appropriate action" [15].
Therefore, interdependence is invaluable (between parents and friends). Chinese people attach great importance to the warm human relationship and the harmonious relationship. Under the strong influence of "relationship oriented", "lasting relationship based on the good feelings between oneself and others" has become a common practice of Chinese people, and the goal of communication harmony is the ultimate goal. The Chinese people are collectivism. They strive for the goals and values of the team, with mutual benefit, consistency, modesty, and prudence. Face and face-work are stressed.

Moreover, the principles of Ren (being benevolent) and $\mathrm{Li}$ (the rules of proper social conduct), the core concepts of Confucianism, help reinforce the vertical relationship by advocating the maintenance of status and role differences between people.

In a word, the vertical structure of Chinese society and the strong influence of Confucianism on Chinese people are an important context in the conceptualization of politeness. Therefore, the perception of Chinese politeness, its realizations and standards need to be related to such a context. In this case, people will expect some cultural differences to be different from English politeness.

3.2.3. Reflecting on philosophical tradition. The most approximate equivalent of the English word "politeness", in modern Chinese, is Limao, which morphemically means "polite appearance". Limao is regarded as the classic concept of Ren and $\mathrm{Li}$ in history, which was proposed by Confucius, an ancient Chinese philosopher and thinker.

Confucius lived in the era of the decline of slavery, and in the environment of wars between feudal states. Chinese people's politeness concept has strong moral and political goals, because it helps to maintain social hierarchy and social order. This is also the tradition of politeness research in Chinese culture. The study of politeness in Chinese culture is holistic rather than descriptive. Chinese scholars often regard politeness as a political or moral issue, rather than a language one.

Later, the word "Li" seems to be used in a sense very close to the derivative of modern Chinese, that is, "Limao". It was first found in a book-Li Ji (The Book of Rites), which is the first systematic work on politeness. In fact, it is far from the book of linguistics, but a book that tells people what proper behavior is in a particular social environment. As a result, it is by no means descriptive but prescriptive. That is to say, its purpose is to lay down a set of appropriate behaviors and appropriate codes with the purpose of cultivating people in good rules and respect for social hierarchy and consolidate the feudal sovereignty.

3.2.4. Towards "privacy" and "attitudinal warmth". Privacy is valuable in all cultures, but it is 
more valued in western culture. Chinese people attach great importance to mutual concern, which is as important as modesty. For example, Chinese people sometimes like to make direct comments on some private affairs, or to make direct suggestions to care for the welfare of others. Gu yueguo has rightly included "attitudinal warmth", a highly regarded trait in Chinese culture, as one of the four notions underlying the Chinese conception of Limao. In Chinese culture, showing warmth and concern is a kind of polite behavior. This is why the first meeting of two Chinese people may ask each other's age, marital status, occupation and income.

This is in conflict with the personal privacy of Western culture. Native speakers of English have a strong sense of privacy and are easily offended by comments that seem to be violating their personal lives. "Where are you going?" Such greetings are particularly distasteful to them. In China, many foreign teachers complain that their room attendants are all spies because they greet their "where you are going". Chinese people think it is polite for them to care about others. But these effects are contrary to their goodwill. In Chinese culture, this is not an impolite act, but a kind of expression of concern and kindness. But if people in the West ask such a question, they think their interaction is a violation of their privacy.

\section{Reflexivity in language intercultural communication issues}

and

Having discussed the factors that could cause the differences between English and Chinese greetings, we proceed to discuss the problems of greeting in intercultural communication, and to call for further cross-cultural studies of linguistic routines of politeness. Hence, it is important and urgent to raise our intercultural awareness and to develop our communicative competence so as to minimize and avoid pragmatic failure and enjoy successful communication across cultures.

Some issues and communicating failures happened in intercultural communication are easily found in language routines, such as greetings in English and Chinese. Because of cultural differences, there may be some misunderstandings. Although the language used in communication may be faultless, the same words may not mean the same thing to different people. As far as language politeness is concerned, it has great differences in the pragmatic use, realization and judgment standards of intercultural communication. With understanding of these differences, improper use of politeness in intercultural communication often causes pragmatic failure and a region of communication problems. It may also occur in the internal environment of culture, but is often exacerbated by cultural differences. As mentioned earlier, a foreign teacher was annoyed by such questions as "Where are you going?" and "What are you doing?" from Chinese speakers of English, who actually tried to be polite to him.

In fact, different social and cultural assumptions emphasize that the construction of information on the discourse level is not easy to identify. In principle, one cannot expect to translate their regular expressions into another language and have the same effect in the target language. But in practice, the interference of mother tongue to foreign languages seems to be unavoidable for foreign language learners. People from different cultural backgrounds try to make a reasonable explanation when facing a strange way of speaking, and rely on their evaluation framework to acquire knowledge through their own culture.

Since misunderstanding can easily occur, some linguists suggest that we should consider the way of expression of greetings in English and Chinese, and how important the differences between these two cultures are. It is important to remember that the rules of communication are both important to the combination of culture and content. This means that if we want to succeed in intercultural communication, we need know not only the rules of our own culture but that of the culture of the person with whom we are interacting. The key is to get enough knowledge and be willing to accept cultural differences in communication.

\section{Developing intercultural awareness and promoting intercultural communication competence}

Being fully aware of intercultural differences requires a deeper study of the culture involved. Comparatively speaking, we are familiar with our native culture. Therefore, we should make use of all kinds of sources (books, movies, videos, etc.) to understand the target culture as much as possible.

In addition, intercultural contrast will also be an indispensable way for foreign culture. More attention should be paid to the differences that may cause intercultural misunderstanding and conflict. The information obtained in intercultural studies will provide a better understanding of the basis of other cultures and thus avoid ethnocentrism.

That is to say, be willing to accept the differences in the two cultures. Acceptance means that we are trying to understand or accept a pattern of social behavior, a pattern of thinking ways, which is not good or bad, not our own, but different from us. Learn to tolerate people of the other culture. It is very important for both sides to take a tolerant, understanding and mutually important position in intercultural communication. 
Since cultural differences exist objectively, members of a specific culture always show their cultural values. In an intercultural environment, each participant should make his or her communicative behavior fit in with each other's values. Adaptation means respect for another value system. Without such respect, one cannot adapt his or her communication to other systems. Therefore, adapting to each other's value system is the key to the success of intercultural communication.

The ability of using greetings is an essential part of communicative competence. As Ferguson [16] has points out, "some politeness routines, like greetings, are universal phenomena in human languages, and it is important to include an account of their acquisition in our ethnographies of communication." The necessity and urgency of acquiring intercultural communicative competence is self-evident.

Communicators should be well aware in the target culture in terms of culture learning. They should enhance their cultural sensitivity and realize that intercultural communication competence can by no means be acquired by the mere mastery of language forms. They should consciously reflect different and contrastive cultural facts and assumptions in language points. What is more, language learners are encouraged to participant in the activity in interaction.

In addition to assisting in the language learning, exposure to authentic materials can also aid in discovering some cultural elements of the target cultural context. But what learners really have to learn is how to put this knowledge to use in varying situational contexts for varying purposes, for the benefit of varying conversational partners.

\section{Conclusions}

The study focuses on greetings reflects sociocultural differences in the notion of people between English and Chinese. The term greeting should be taken in a fairly general sense to mean a simple utterance expressing recognition of another person's presence. Greetings are exchanged not in order to inform, not in the case to connect people in action, but to convey the social relationship that the speakers assume or try to establish. Greetings are important tools for achieving certain communicative goals and they are required to study carefully.

It is found that differences in the content or overt messages conveyed by routine expressions in English and Chinese greeting processes suggests that what counts as polite in one language may not do so in another. The notion of degree of politeness is inherent in linguistic routines as perceived by speakers of English and Chinese. It cannot be neglected in the model of politeness. Although the use of linguistic routines is constrained by common social factors, cultural factors, the actual use varies from person to person and from language to language.

The use of English greetings in intercultural communication is much more problematic than what people may think. It is necessary for us to understand and strengthen our intercultural communication competence. The issue of whether or not politeness is a universal value is quite delicate and controversial. But the cultural specificities of politeness do not indicate that there are no universal areas where cultures overlap, since the fact that there is the possibility of intercultural communication is most likely to indicate that there is some common ground on which studies of politeness may be based. Therefore, greetings as linguistic routines for initiating language contact in both native and foreign language contexts require more intensive and extensive studies, which can promote understanding between speakers of different languages and cultures.

\section{Acknowledgment}

This study was supported by Beijing University of Posts and Telecommunications- Postgraduate Educational Reform Project (2018Y023).

\section{References}

[1] Agha, A., (2007), Language and social relations, Cambridge: Cambridge University Press, pp.1-2.

[2] Laver. J., (1981), "Linguistic Routines and Politeness in Greetings and Partings", In Coulmas, F., editor, Conversational Routine, The Hague: Mouton, pp.289-304.

[3] Goffman, E., (1967), Interaction Ritual: Essays on Face to Face Behavior, Anchor Books.

[4] Ferguson, C.A., (1976), "Structure and use of politeness formulas", Language in Society, 5(2), pp.129136.

[5] Hymes, D., (1968), The Ethnography of Speaking. In J. A. Fishman (Ed.). Readings in Sociology of Language. The Hague: Mouton Publishers. ---(1972). Toward Ethnographies of Communication: The Analysis of Communicative Events. In Giglioli. P. P. (Ed.). Language and Social Context, pp. 21-44. Penguin books.

[6] Schegloff, E. and H. Sacks, (1973). Opening Up Closings. In R. Turner (Ed.), pp. 233-264.

[7] Richards, J. C. and R. W. Schmidt, (Eds.) (1983). Language and Communication. London and New York: Longman, pp.131-132.

[8] Goffman, E., (1967), Interaction Ritual: Essays on Face to Face Behavior, Garden City, New York: Doubleday and col, Inc.

[9] Goffman, E., (1971), Relations in Public: Microstudies of the Public Order. New York: Basic Books, pp.74-75. 
[10] Firth, J. R., (1972). Verbal and Bodily Rituals of Greeting and Parting. In J. S. LaFontaine (Ed.). The Interpretation of Ritual, pp. 1-38.

[11] Brown, P. and S. Levinson, (1978, 1987). Politeness: Some Universals in Language Usage. Cambridge: Cambridge University Press.

[12] Fieg, J. and Mortlock, E., (1989). A Common Core: Thais and Americans. Yarmouth: Intercultural Press, Inc.

[13] Spencer-Oatey, H., (1996). Reconsidering Power and Distance. Journal of Pragmatics 26, pp.1-24.

[14] Samovar, L. A. and Porter, R. E., (1995), Communication Between Cultures. New York: Wadsorth Publishing Company.

[15] Hu Wenzhong, (1999), Aspects of Intercultural Communication. Beijing: Foreign Language Teaching Education and Research Press.

[16] Ferguson, C.A., (1976) Structure and use of politeness formulas. Language in Society 5, pp.129-136.

[17] O'Dowd, R., (2007) Online Intercultural Exchange: An Introduction for Foreign Language Teachers. Bristol: Multilingual Matters

[18] Preisler, B., Klitgard, I., and Fabricius, A., Language and Learning in the International University: From English Uniformity to Diversity and Hybridity (Languages for Intercultural Communication and Education), Bristol: Multilingual Matters.

[19] Gu, Yueguo, (1990), Politeness phenomenon in modern Chinese, Journal of Pragmatics, pp.237-257.

[20] Jia, Yuxin, (1997), Cross-culture Communication, Shanghai: Shanghai Foreign Language Education Press.

[21] Qian, Housheng, (1996), Greetings and Partings in English and Chinese: A Contrastive Study of Linguistic Routines and Politeness, Shanghai: Shanghai Foreign Language Education Press. 